Proceeding Paper

\title{
Determination of the Safest Route for Logging Trucks Based on Road Types and Conditions ${ }^{\dagger}$
}

Abdullah E. Akay

Citation: Akay, A.E. Determination of the Safest Route for Logging Trucks Based on Road Types and Conditions. Environ. Sci. Proc. 2021 3, 5. https://doi.org/10.3390/ IECF2020-08068

Academic Editors: Angela Lo Monaco; Cate Macinnis-Ng and Om P. Rajora

Published: 13 November 2020

Publisher's Note: MDPI stays neutral with regard to jurisdictional claims in published maps and institutional affiliations.

Copyright: $\odot 2020$ by the authors. Licensee MDPI, Basel, Switzerland. This article is an open access article distributed under the terms and conditions of the Creative Commons Attribution (CC BY) license (http://creativecommons.org/licenses/by/4.0/)
Faculty of Forestry, Bursa Technical University, 16310 Yıldırım Bursa, Turkey; abdullah.akay@btu.edu.tr + Presented at the 1st International Electronic Conference on Forests - Forests for a Better Future: Sustainability, Innovation, Interdisciplinarity, 15-30 November 2020; Available online: https://iecf2020.sciforum.net.

\begin{abstract}
Hauling of wood-based forest products is a complex problem that requires evaluation of many alternative routes. Forest transportation has been generally done by using logging trucks with high carrying capacity. Logging truck driving is one of the dangerous occupations in forestry, particularly in Turkey, where forest lands are mostly located in mountainous regions with steep slopes. The safety risk of truck driving mainly depends on the road standards and conditions. The majority of the forest roads in Turkey have low standards that limit the maneuverability of logging trucks. In such conditions, forest transportation should be planned by considering not only transportation costs but also the safety of logging truck driving. In this study, the GIS-based network analysis method was used to develop the optimum transportation plans for two scenarios. In the first scenario, an optimum plan that minimized the total transportation cost was developed, while a transportation plan that ensured the safest logging truck driving was optimized in the second scenario. A safety score was assigned to each road section based on the road type (asphalt, gravel, forest road) and road conditions (good, medium, poor). In the study area, located in the city of Bursa in Turkey, there were three forest depots and five landings. The results indicated that the transportation cost increased by $15.76 \%$ when the safety of logging truck driving was prioritized. In this scenario, forest products from three landings were transported to different depots, compared to the first scenario.
\end{abstract}

Keywords: forest roads; transportation cost; truck driving safety; GIS

\section{Introduction}

Hauling of timber from landing areas to forest depots is an important stage in producing wood-based forest products. Inadequately planned forest transportation can be the most expensive stage of timber production [1]. To develop adequate transportation planning, many alternative transportation routes should be evaluated. Computer-based methods have been used to evaluate alternative transportation plans and to determine the optimum plan with minimum cost $[2,3]$.

Forest transportation is generally performed by using logging trucks, and driving a logging truck is considered as one of the dangerous occupations in forestry, particularly in Turkey, where forest lands are mostly located in mountainous regions. The safety risk of truck driving mainly depends on the road standards. In Turkey, the majority of forest roads $(66 \%)$ are secondary forest roads, which are usually subject to annual major repair needs due to low road standards [4]. The standards of these roads limit the maneuverability of logging trucks with high load capacity [5]. Thus, forest transportation should be planned by considering not only transportation costs but also the safety of logging truck driving.

Planning of forest transportation activities is very crucial in order to minimize organizational risks and to lower down transportation cost [6]. The computer-based network 
analysis method provides accurate and quick solutions for solving transportation problems such as shortest path and maximum flow [7]. In the solution process of forest transportation planning with minimum cost, various parameters such as road length, travel time, and transportation unit cost are assigned to the road links, and then the optimal path is determined by searching the alternatives [8]. In order to search for transportation planning with safety constraints, specific parameters such as road standards and road conditions should be taken into consideration [9].

It is possible to integrate the network analysis method with GIS techniques for the quick and accurate evaluation of alternative routes. Especially, the Network Analyst tool of ArcGIS software can be efficiently used for solving transportation problems. Bonazountas et al. [10] describe a decision support system for managing forest casualties in which the access time of vehicles to a fire is calculated using GIS network analysis tools. A raster-based road network with impedance values was used to calculate access time, including water re-charging cycles.

Akay and Kakol [11] developed a GIS-based decision support system to determine the optimum route that minimized the total cost of transporting forest products. The network analysis method under the "network analyst" extension of the ArcGIS program was applied. They reported that using a GIS decision support system reduced transportation costs by $28.29 \%$. In a study conducted by Podolskaia et al. [12], traveling time and distance to a forest fire were estimated using the transport network model generated by the network analyst tool in ArcGIS. A map of the fire ground protection zone was produced to evaluate ground transport accessibility for three time periods (one, two and three hours).

In this study, a GIS-based network analysis method was used to develop the optimum transportation plans considering the cases of minimum transportation costs and minimum driving risk. In the first case, transportation planning with minimum transportation cost was developed, while transportation planning with the safest truck driving was determined in the second case. In the second case, the road type (asphalt, gravel, forest road) and road conditions (good, medium, poor) were considered to assign safety scores to road sections.

\section{Methods}

\subsection{Study Area}

The study area is Paşalar Forest Enterprise Chief (FEC), located on the border of M.Kemal Paşa Forest Enterprise Directorate (FED) in the city of Bursa in Turkey. Three forest depots (Paşalar, Karapınar, Sünlük Depots) and five sample landing areas in the FEC were considered in the study. The location of depots, landings, and amount of forest products hauled from each landing area were obtained from the FED (Figure 1).

\subsection{Road Network}

The road network layer was generated based on the topographic map that was obtained from the FED. Five parameters (road length, road type, road condition, average vehicle speed, travel time, and road safety score) were assigned to each road section into the "attribute table" of the road network layer. The road length was calculated by the "calculate geometry" tool in the "attribute table". The road types (asphalt, gravel, forest road) and road conditions (good, average, poor) were determined based on information obtained from the FED. Then, the average vehicle speed was computed based on road types and road conditions (Table 1). 


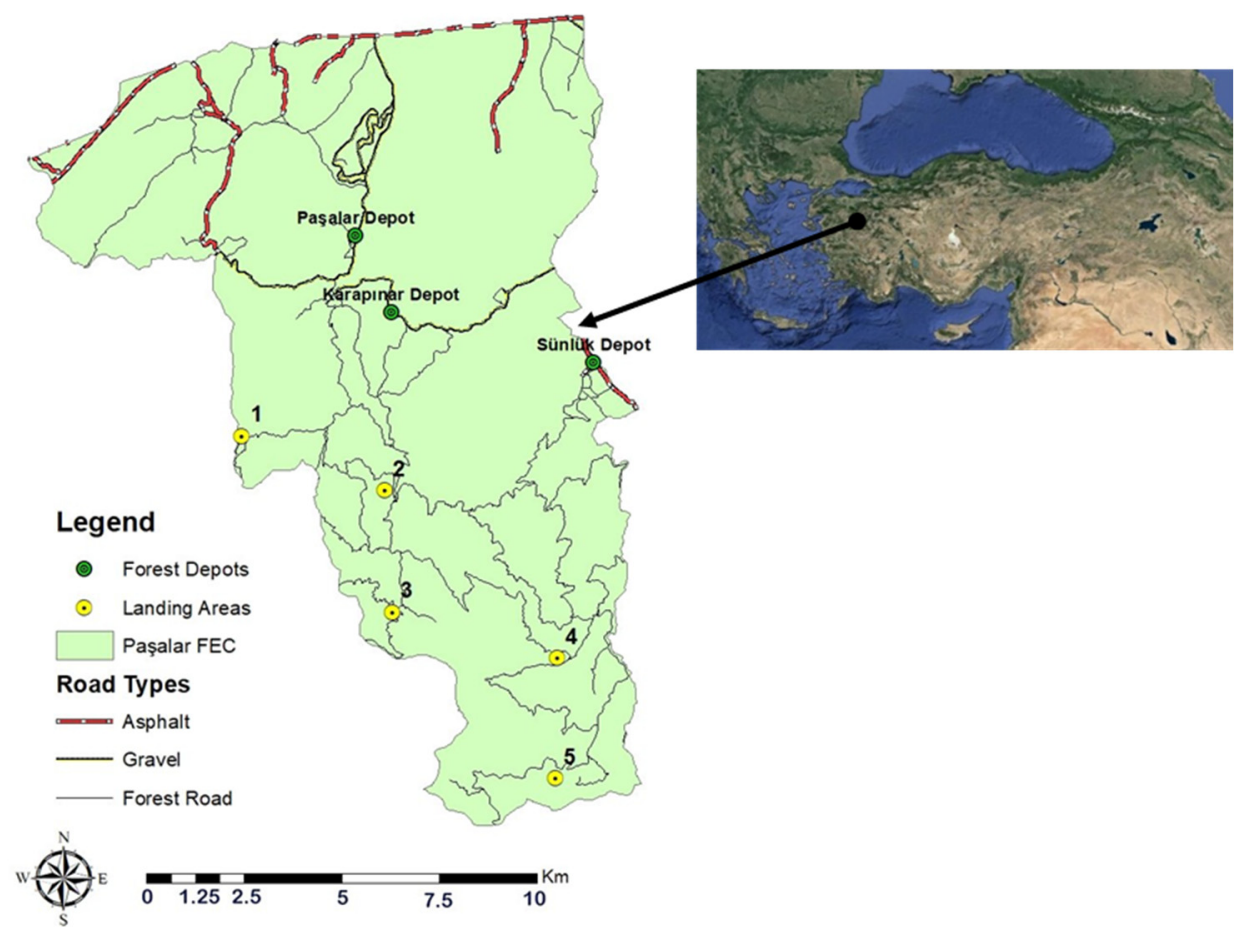

Figure 1. Study area.

Table 1. The average logging truck speed (km/hour) for road types and conditions.

\begin{tabular}{cccc}
\hline \multirow{2}{*}{ Road Type } & \multicolumn{3}{c}{ Road Conditions } \\
\cline { 2 - 4 } & Good & Medium & Poor \\
\hline Asphalt road & 60 & 50 & 40 \\
Gravel road & 40 & 30 & 20 \\
Forest road & 25 & 20 & 15 \\
\hline
\end{tabular}

The travel time of the logging truck for each road section was computed based on road length and vehicle speed:

$$
t_{i}=\frac{l_{i}}{v_{i}} 60
$$

$t_{i:}$ travel time on road section $i$ (minutes);

$l_{i}$ : length of road section $i(\mathrm{~km})$;

$v_{i}$ : vehicle speed on section $i(\mathrm{~km} / \mathrm{h})$;

60: coefficient to convert time from hours to minutes

After computing travel time for each road section, transportation cost $\left(€ / \mathrm{m}^{3}\right)$ was computed based on machine rate $(€ / \mathrm{h})$, truck load capacity $\left(\mathrm{m}^{3}\right)$, and travel time $(\mathrm{h})$ :

$$
C_{i}=\frac{M R}{\left(\frac{\text { load }}{t_{i}}\right) * 60}
$$

Ci: transportation cost $\left(€ / \mathrm{m}^{3}\right)$;

load: load capacity $\left(\mathrm{m}^{3}\right)$;

MR: machine rate $(€ / \mathrm{h})$

Within the scope of the study, a logging truck commonly used in the region was taken into consideration. The load capacity and machine rate of the truck was 15 ton and 9.37 $€ / \mathrm{h}$, respectively.

The road safety score was determined by an expert choice approach, depending on road type and road conditions. The relative safety score of road sections was evaluated based on a numerical scale from 1 to 9 . When the risk was high, the higher score was given 
to the road sections (Table 2).

Table 2. The road safety score for road types and conditions.

\begin{tabular}{cccc}
\hline Road Type & Good & $\begin{array}{c}\text { Road Conditions } \\
\text { Medium }\end{array}$ & Poor \\
\hline Asphalt road & 1 & 2 & 3 \\
Gravel road & 4 & 5 & 6 \\
Type-B forest road & 7 & 8 & 9 \\
\hline
\end{tabular}

\subsection{Network Analysis}

The "network analyst" extension in ArcGIS provides network-based spatial analysis, including routing, service area, closest facility, travel directions, and new location-allocation analysis. Using a sophisticated network model, users can easily build networks based on a GIS database. In this study, the "new closest facility" method within the "network analyst" extension was implemented to explore optimum routing solutions for two scenarios. In the first scenario, transportation planning with minimum transportation cost was developed. The transportation cost was assigned to the links that represented the road sections in the network database.

In the second scenario, transportation planning that ensured the safest logging truck driving was developed. The safety score was assigned to the links that represented the road sections in the network database. Finally, both scenarios were compared in terms of total transportation costs and hauling route of forest products from each landing.

\section{Results and Discussion}

In this study, the GIS-based network analysis method was used to develop the optimum transportation plans for two scenarios prioritizing minimum transportation cost and the safest transportation. The results indicated that the total transportation cost was $€ 4238.22$ in the first scenario (Table 3). It was found that the forest products from one landing (Landing 1) were hauled to Paşalar Depot, from two landings (Landing 2 and 3) to Karapınar Depot, and other two landings (Landing 4 and 5) to Sünlük Depot. Figure 2 indicates the optimum transportation routes for each scenario.

Table 3. Transportation costs summary for the first scenario.

\begin{tabular}{|c|c|c|c|c|}
\hline Landings & Depots & Timber Volume $\left(\mathrm{m}^{3}\right)$ & Unit Cost $\left(€ / \mathrm{m}^{3}\right)$ & Transportation Cost $(€)$ \\
\hline \multirow{3}{*}{1} & Paşalar & & 0.65 & 160.21 \\
\hline & Karapinar & 246 & 0.67 & 164.01 \\
\hline & Sünlük & & 1.56 & 383.27 \\
\hline \multirow{3}{*}{2} & Paşalar & & 0.68 & 601.25 \\
\hline & Karapinar & 887 & 0.55 & 487.80 \\
\hline & Sünlük & & 0.98 & 867.56 \\
\hline \multirow{3}{*}{3} & Paşalar & & 0.93 & 357.58 \\
\hline & Karapınar & 383 & 0.81 & 308.60 \\
\hline & Sünlük & & 1.23 & 472.57 \\
\hline \multirow{3}{*}{4} & Paşalar & & 1.38 & 3326.10 \\
\hline & Karapinar & 2407 & 1.25 & 3018.25 \\
\hline & Sünlük & & 1.11 & 2674.71 \\
\hline \multirow{3}{*}{5} & Paşalar & & 1.87 & 776.12 \\
\hline & Karapınar & 415 & 1.74 & 723.04 \\
\hline & Sünlük & & 1.46 & 606.90 \\
\hline
\end{tabular}



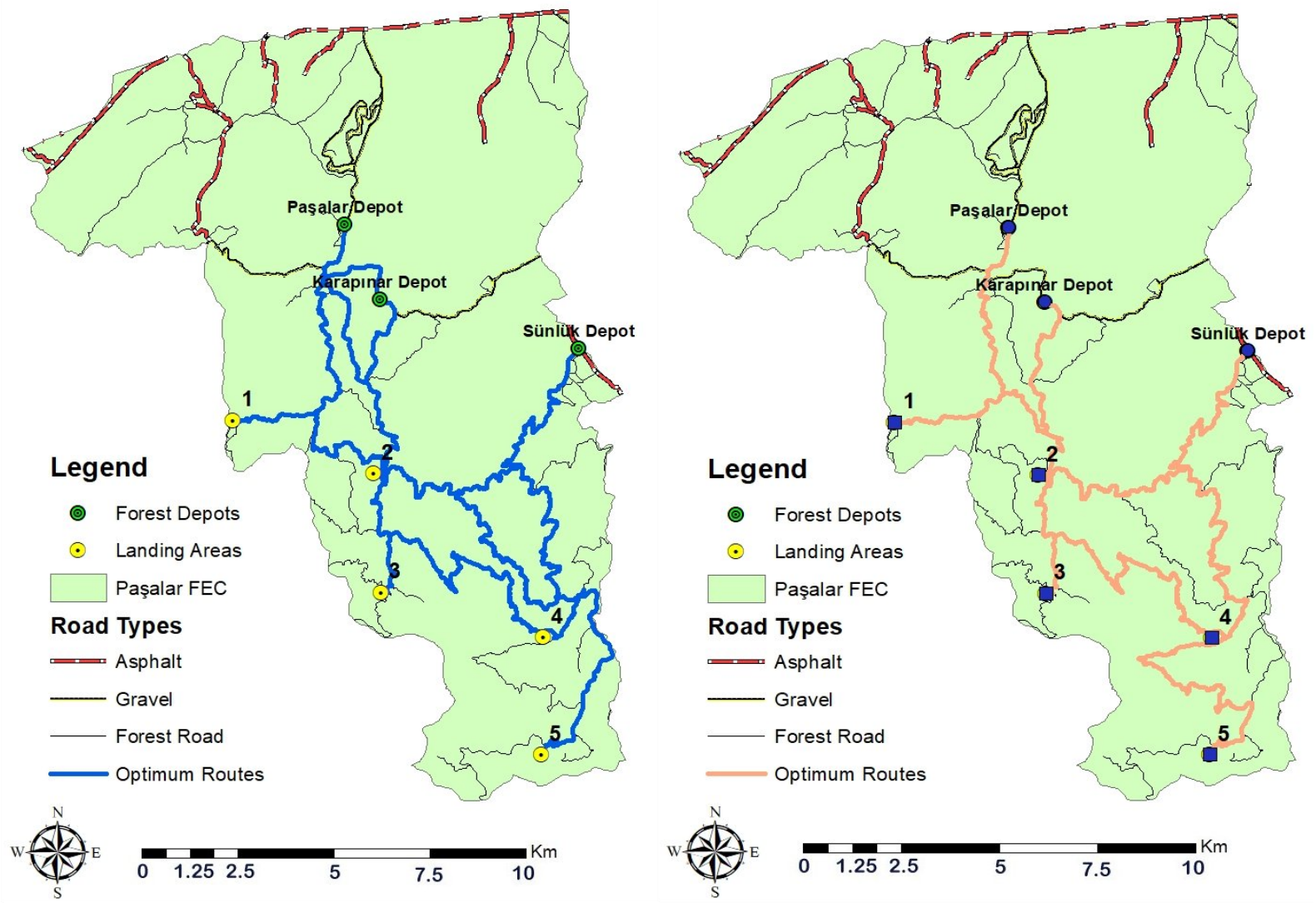

Figure 2. Optimum routes for the first (left) and the second (right) scenario.

In the second scenario, the results indicated that the total transportation cost was $€ 4906.29$ (Table 4). Thus, the transportation cost increased by $15.76 \%$ when the safety of logging truck driving was prioritized. It was found that the forest products from all of the landings were hauled to Karapinar Depot.

Table 4. Transportation costs summary for the second scenario.

\begin{tabular}{|c|c|c|c|c|c|}
\hline Landings & Depots & Timber Volume $\left(\mathrm{m}^{3}\right)$ & Safety Scores & Unit Cost $\left(€ / \mathrm{m}^{3}\right)$ & Transportation Cost $(€)$ \\
\hline \multirow{3}{*}{1} & Paşalar & & 75 & \multirow{3}{*}{0.69} & \multirow{3}{*}{169.58} \\
\hline & Karapınar & 246 & 53 & & \\
\hline & Sünlük & & 100 & & \\
\hline \multirow{3}{*}{2} & Paşalar & & 76 & \multirow{3}{*}{0.55} & \multirow{3}{*}{490.81} \\
\hline & Karapınar & 887 & 38 & & \\
\hline & Sünlük & & 67 & & \\
\hline \multirow{3}{*}{3} & Paşalar & & 115 & \multirow{3}{*}{0.85} & \multirow{3}{*}{326.95} \\
\hline & Karapınar & 383 & 77 & & \\
\hline & Sünlük & & 106 & & \\
\hline \multirow{3}{*}{4} & Paşalar & & 107 & \multirow{3}{*}{1.25} & \multirow{3}{*}{3006.64} \\
\hline & Karapinar & 2407 & 69 & & \\
\hline & Sünlük & & 76 & & \\
\hline \multirow{3}{*}{5} & Paşalar & & 133 & \multirow{3}{*}{2.20} & \multirow{3}{*}{912.31} \\
\hline & Karapınar & 415 & 95 & & \\
\hline & Sünlük & & 101 & & \\
\hline
\end{tabular}




\section{Conclusions}

An application of the GIS-based network analysis method was implemented to determine the optimum route for transporting forest products. The optimum routes were searched for two scenarios, including minimum transportation cost and the safest transportation. The results indicated that the total cost of transportation in the first scenario was less than that of the second scenario. The results suggested that the most important factors affecting the productivity of transportation were the road type, road length, road condition. In fact, road type and road conditions were also the most important factors on transportation safety. In order to ensure the safe driving of logging trucks, forest roads should be properly reconstructed and regularly maintained considering the technical and safety requirements. Although reengineering of the forest roads requires some investment, improved forest roads will provide better access to forest resources for many forestry activities such as reforestation, protection, management, logging operations, and recreations.

Funding: This research received no external funding.

Conflicts of Interest: The authors declare no conflict of interest.

\section{References}

1. Acar, H.H.; Eroğlu, H. The Planning of Wood Transport on the Forest Roads. Kafkas University. Artvin Fac. For. J. 2001, 1, 61-66.

2. Aruga, K.; Sessions, J.; Akay, A.E. Heuristic Techniques Applied to Forest Road Profile. Jpn. For. Soc. J. For. Res. $2005,10,83-92$.

3. Akay, A.E.; Doucas, K.; Erdaş, O.; Oğuz, H.; Sivrikaya, F. Using GIS Techniques to Determine Fire Protection Zones Considering Forest Road Network. In Proceedings of the Forest Engineering: Concern, Knowledge and Accountability in Today's Environment, Hotel Croatia, Dubrovnik (Cavtat), Croatia, 8-12 October 2012.

4. GDF. Strategic Plan (2013-2017); General Directorate of Forestry, Strategy Development Department: Ankara, Turkey, 2012; 98p.

5. Buğday, E.; Menemencioğlu, K. Assessment of Existing Forest Road Standards Conformity for Stumpage Sale in Turkey, II. In Proceedings of the National Mediterranean Forest and Environment Symposium, Isparta, Turkey, 22-24 October 2014.

6. Akay, A.E.; Erdaş, O. Network Model Approach in Transportation Planning of Forest Products.İstanbul University. Fac. For. J. A-Ser. 2007, 57, 1-20.

7. Akay, A.E.; Wing, G.M.; Sivrikaya, F.; Sakar, D. A GIS-Based Decision Support System for Determining the Shortest and Safest Route To Forest Fires: A Case Study in Mediterranean Region of Turkey. EMAS 2012, 184, 1391-1407.

8. Chung, W.; Sessions, J. Optimization of Cable Logging Layout Using a Heuristic Algorithm for Network Programming. In Proceedings of the Council of Forest Engineering, Auburn, AL, USA, 16-20 June 2002; 104p.

9. Dijkstra, A.; Drolenga, H.; van Maarseveen, M. Method for Assessing Safety of Routes in a Road Network. Transp. Res. Record. 2007, 2019, 82-90. doi:10.3141/2019-11.

10. Bonazountas, M.; Kallidromitou, D.; Kassomenos, P.; Passas, N. A decision support system for managing forest fire casualties. J. Environ. Manag. 2007, 84, 412-418.

11. Akay, A.E.; Kakol, A.A.H. Forest Transportation Planning by using GIS-based Decision Support System. In Proceedings of the 5th Forest Engineering Conference with 47th International Symposium on Forestry Mechanisation, Gerardmer, France, 23-26 September 2014.

12. Podolskaia, E.S.; Kovganko, K.K.; Ershov, D.V.; Shulyak, P.P.; Suchkov, A.I. Using of transport network model to estimate travelling time and distance for ground access a forest fire. For. Sci. Issues 2019, 2, 1-24. 